\title{
Influence of nutrition during late pregnancy on dam condition, foetal growth and gestation length
}

\author{
G.W. ASHER 1 and R.C. MULLEY ${ }^{2}$ \\ ${ }^{1}$ AgResearch, Invermay Agricultural Centre, Private Bag 50034, Mosgiel, New Zealand \\ ${ }^{2}$ Faculty of Agriculture and Rural Development, University of Western Sydney, Richmond, NSW 2753, Australia.
}

\begin{abstract}
Many aspects of the relationship between nutrition and reproductive performance of red deer hinds are poorly understood. One such example is the feed requirements of hinds during the late stages of pregnancy, for which there is considerable diversity of opinion. The present study aimed to relate feed intake of hinds during the last trimester of pregnancy to dam body condition, foetal development and calf growth. Across 3 years, multiparous $(n=33)$ or primiparous $(n=18)$ hinds with known conception dates were housed in individual pens from days 150 to 220 of pregnancy, during which time they were each offered one of three ( $\mathrm{H}, \mathrm{M}$ and $\mathrm{L})$ daily allowances of pelletised rations. Hinds were returned to pasture at day 220 and calving was closely monitored. Liveweight, body condition score (BCS), and lactation score (LS) were recorded weekly from day 150 through to calf weaning at 12 w eeks of age. Additionally, hinds in the first year of study underwent CT scans on days 150 and 215 of pregnancy to assess compositional changes of the dam and conceptus. Mean daily ad libitum intakes of $\mathrm{H}$ hinds increased from 1.8 to $3.2 \mathrm{~kg}$ DM (0.6 to $0.9 \mathrm{MJME} / \mathrm{kg}^{0.75}$ ) between days 150 and 220. Those of restricted $\mathrm{M}$ and $\mathrm{L}$ hinds peaked at 1.8 and $1.6 \mathrm{~kg}$ DM, respectively, by day 220. This was reflected in significant treatment effects on liveweight gain and change in BCS and LS by calving. CT scans indicated a significant treatment effect by day 215 on the mass of hind tissues and a non-significant trend on conceptus weights. There were no discernable treatment effects on calf birth weights. However, there was an unexpectedly wide spread in calving dates that reflected considerable variation in gestation length. Gestation length was significantly negatively correlated to change in hind liveweight (but not BCS) between days 150 and 220 of pregnancy. Of three neonatal calf mortalities, none were related to dystocia or non-viability. Subsequent growth rates of surviving calves did not reflect prior treatment of their dams, although variation in birth date influenced weights at specific dates. It is concluded from this study that while variation in nutrition of hinds during the last trimester may influence foetal development, variation in gestation length compensates to ensure optimisation of birth weight.
\end{abstract}

Keyw ords: gestation, nutr ition, pregnancy, red deer

\section{Introduction}

The last trimester of pregnancy of red deer hinds, when the conceptus acquires $>70 \%$ of its ultimate mass (Adam et al. 1988), coincides with the spring pasture "flush" on New Zealand deer farms. While this alignment outwardly seems desirable given the increasing energy demands of the conceptus, there are often questions raised about the appropriate nutritional management during late pregnancy to optimise neonate survival and growth i.e. balancing the putative consequences of luxury versus restrictive feeding practices during a crucial phase of foetal development.

Two opposing schools of practice have emerged on New Zealand deer farms in relation to feeding hinds in late pregnancy. The first strategy is to provide maximal nutrition to hinds on the basis that neonate viability is enhanced be increasing birth weight and high body condition score (BCS) of dams by calving time bodes well for impending lactation energy drains. The second strategy seeks to restrict hind access to feed on the belief that unrestricted intake results in increased incidences of neonate/dam mortality due to dystocia as a result of over-developed neonates (i.e. high birth weight) and over- conditioned dams (i.e. obesity).

After 25 years of deer farming in New Zealand, the issue of optimal feeding strategies for hinds in late pregnancy has remained unresolved. This highlights a paucity of information on the relationship between nutrition and reproduction performance in red deer. The present study aimed to relate feed intake of hinds during late pregnancy to dam BCS, foetal development and calf growth. In doing so, we tested the following two hypotheses:

1. Under-nutrition (restricted intake) retards foetal growth and reduces hind energy reserves, leading to reduced birth weights, retarded mammary development and slower calf growth rates.

2. Over-nutrition (ad libitum intake) leads to excessive foetal development and hind fat accretion that inhibits the normal parturition process, resulting in increased incidence of calf mor tality.

\section{Material and Methods}

Each of three trials across consecutive years (1998 2000 inclusive) involved individual indoor housing of 
Figure 1 Profiles of mean $( \pm$ SEM) daily dry matter intake between Days 130 and 220 of gestation of High $(\diamond)$, Medium $(\Delta)$ and Low (O) hinds in Year 1 (1988), Year 2 (1999) and Year 3 (2000). Arrows indicate timing of CT scans in Year 1 and the introduction of a new feed batch in Year 2.

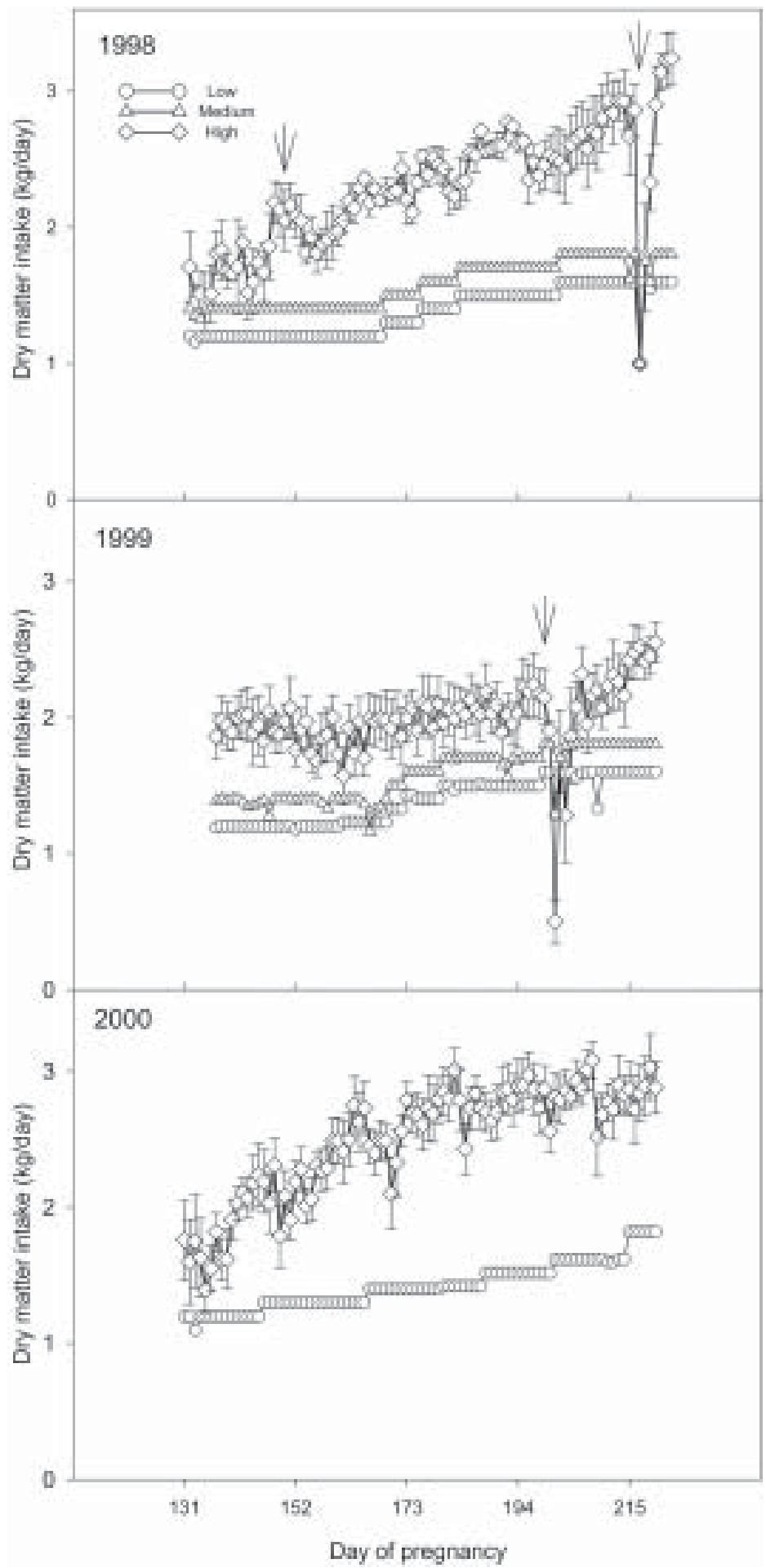

18 pregnant red deer hinds, each gestating a red deer foetus, between days 150 and 220 of gestation. Hinds had their conception dates synchronised by use of intravaginal progesterone-releasing devices (Eazi-breed CIDR- type G; InterAG, Hamilton, NZ) and injection of equine chorionic gonadotophin (Folligon; Intervet, Lane Cove, NSW, Australia). Gestation length was assumed to be $233 \pm 3$ days (Guinness et al. 1971). During indoor housing, the hinds were each subjected to one of three (years 1 and 2) or two (year 3) levels of feed offered. Trials in years 1 and 2 were between-year replicates using adult hinds (i.e. $>4$ years old), whereas the trial in Year 3 used rising-two-year old hinds (i.e. first calvers). Following nutritional treatments, calving and calf growth were monitored.

Hinds were offered a grain-based pelletised ration ("Invermay Formula"; Harraway and Sons Ltd, Dunedin, NZ) containing 11 MJME/ $\mathrm{kg} \mathrm{DM}$ and $16 \%$ crude protein. In addition to pellets, $5 \%$ by weight of daily offer was chaffed lucerne hay to maintain an adequate intake of ruminal roughage. Rations were fed daily and the previous day's refusals were weighed. In Years 1 and 2 (adult hinds) each hind was allocated to either a "High" group (H) receiving ad libitum offer throughout, a "Medium" group (M) offered a daily ration estimated to be $30 \%$ less than the ad libitum intake of $\mathrm{H}$ average over the previous week, and a "Low" group (L) offered a daily ration $50 \%$ less than $\mathrm{H}$ (estimated on the same bases as for $\mathrm{M}$ ). The $\mathrm{M}$ and $\mathrm{L}$ groups received weekly stepwise increases in feed offered during the study to maintain relativity with $\mathrm{H}$ (Figure 1). In year 3 (young hinds), only two feeding levels were applied across the hinds, $\mathrm{H}$ and $\mathrm{L}$ (Figure 1).

At weekly intervals from one week before indoor penning until 12 weeks after calving at pasture, the hinds 
Figure 2 Profiles of mean (+ SED) liveweight of High $(\diamond)$, Medium $(\Delta)$ and Low $(\mathrm{O})$ hinds for each of the years. Split profiles are normalised around both Day of pregnancy and Days from calving to accommodate the wide variation in birthing dates despite a common conception date.

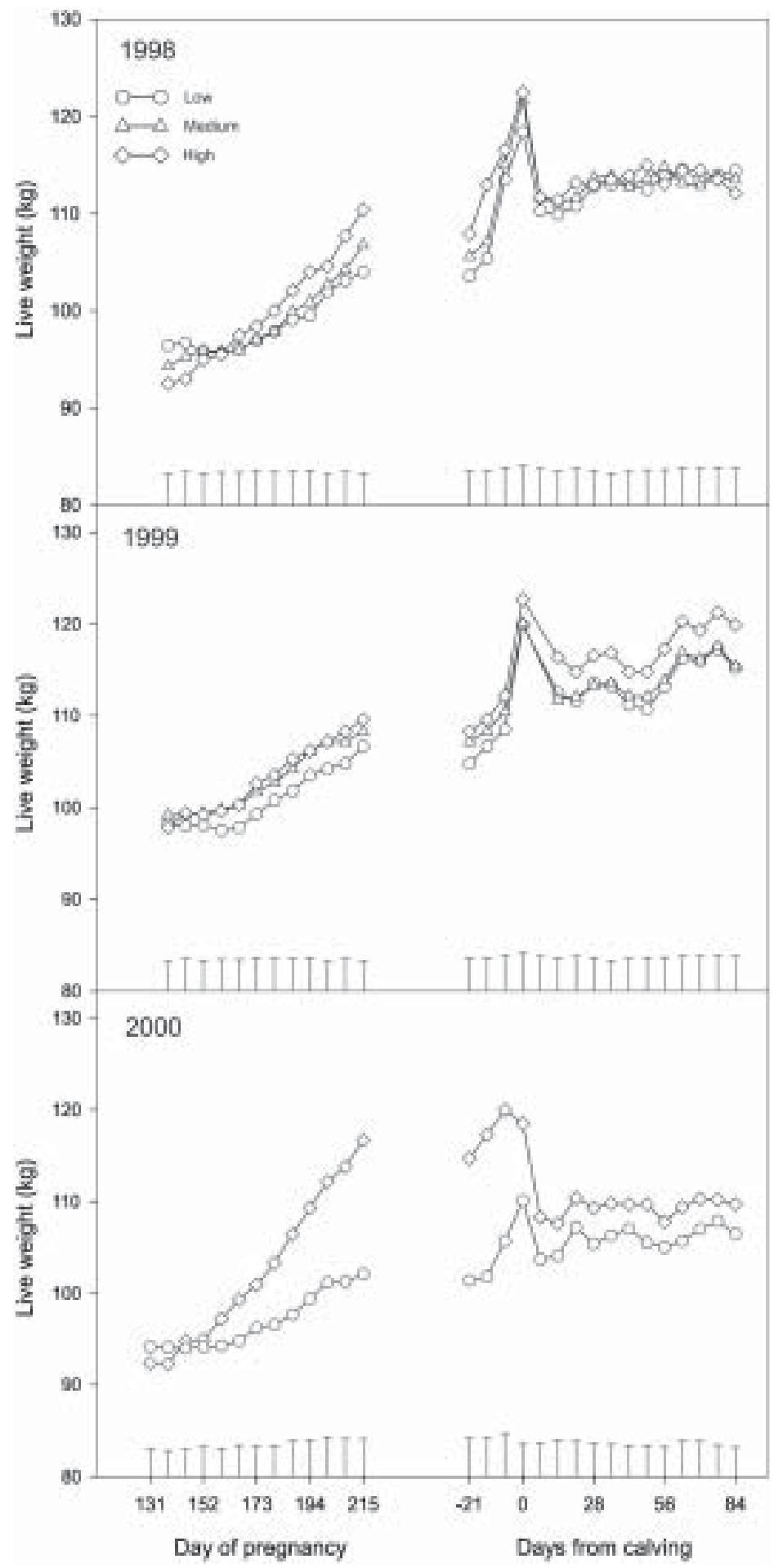

were yarded to record liveweight, BCS (Audigê et al. 1999) and lactation score (an udder palpation score: Asher et al. 1994). Once returned to pasture on day 220 of gestation, the hinds were monitored closely at least twice daily until calving was complete. Calves were tagged within $12 \mathrm{~h}$ of birth and data recorded included birth date, birth weight, sex and dam. Surviving calves remained with their dams for 12 weeks, during which time they were weighed at weekly intervals.

In Year 1 (1998), body composition was measured in the live hinds using CT scanning on two occasions; once at the start of the feeding regimens (day 150) and again 10 w eeks later. Procedures followed those of Jopson et al. (1997). Tissue images of the dam and the conceptus were analysed using the "AutoCAT" programme (Jopson et al. 1995) to assess component tissue weights.

All hind data (except Dry Matter Intake (DMI) and Metabolisable Energy Intake (MEI)) were analysed by ANOVA separately for each year, fitting a term for nutritional treatment. Where the data constituted a repeated measure, they were analysed within two different time frames, firstly synchronised about date of conception and secondly, synchronised about date of birth. Regression analysis was used to investigate relationships between MEI and growth rate, and CT scan data and other explanatory variables.

\section{Results}

The overall analyses involved the complete data sets for 51 (of the original 54) hinds and their calves (including 3 calf mortalities). Three hinds were removed due to various ineligibility factors. All hinds present at calving produced singleton calves. In Year 1, 15 hinds calved after gestations ranging from 218 to 245 days. The first calf was stillborn (see later), but all remaining calves survived to weaning. In Year 2, 18 
Figure 3 Regression of liveweight gain on daily metabolic energy intake/kg0.75 for $\mathrm{H}$ hinds during the period from Days 150 to 220 of pregnancy. Overlay ellipses represent the $95 \% \mathrm{Cl}$ around means for $L$ and $M$ hinds.

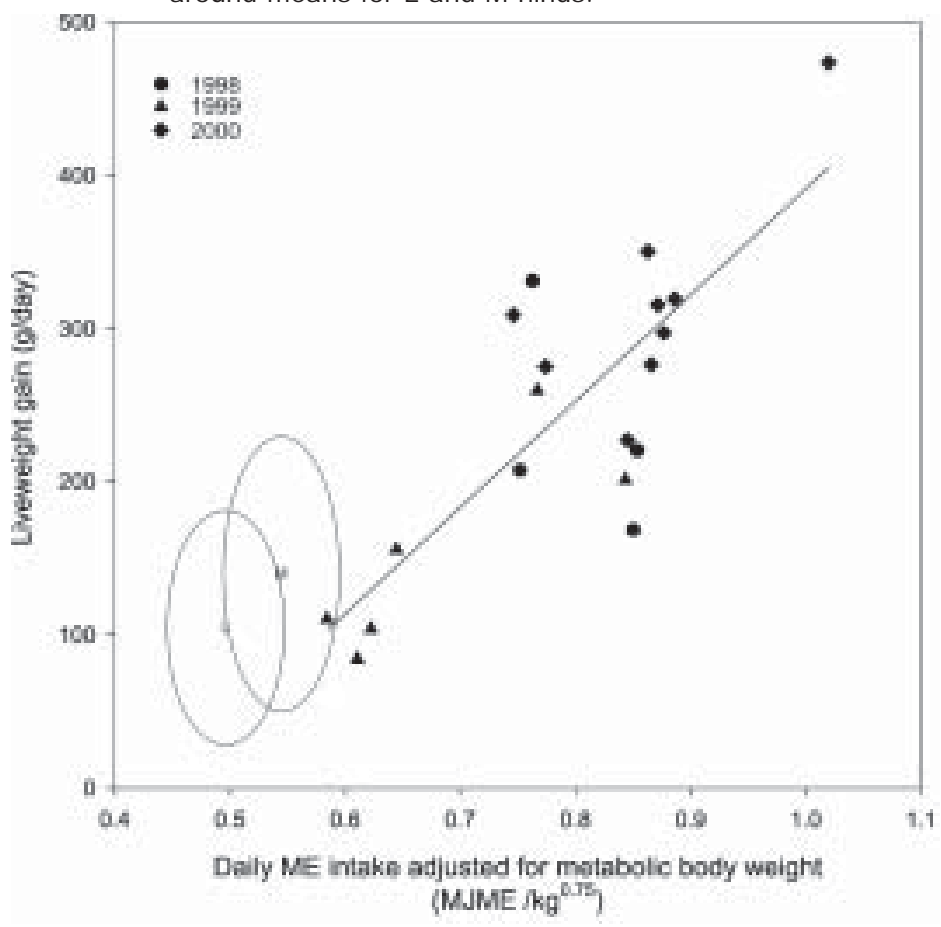

course of late gestation (Figure 1), with means of 1.8-2.0 kg around day 150 and $2.8-3.2 \mathrm{~kg}$ by day 220 . This equated to MEI of 0.6-0.7 and 0.8-0.9 MJME $/ \mathrm{kg}^{0.75}$ for days 150 and 220 respectively. The highest individual daily DMI and MEI recorded during the study occurred amongst the young hinds in Year 3, with one $\mathrm{H}$ hind devouring $>4.0 \mathrm{~kg} \mathrm{DM}$ (i.e. $>1.0 \mathrm{MJME} / \mathrm{kg}^{0.75}$ ) by day 200 of pregnancy. Hinds on restricted intakes exhibited virtually no variation in mean daily DMI due to complete consumption of feed offered (Figure 1).

Positive liveweight gains between days 150 and 220 of pregnancy were a feature of all treatments (Figure 2). However, rates of gain varied considerably between and within treatments, with hinds on ad libitum intake generally gaining considerably more weight prior to calving than $\mathrm{M}$ and $\mathrm{L}$ hinds. The relationship of weight gain during late pregnancy to daily ME intake $/ \mathrm{kg}^{0.75}$ for $\mathrm{H}$ hinds (Figure 3 ) is described by the

hinds calved after gestations ranging from 231 to 242 days and all calves survived. In Year 3, 18 hinds calved after gestations ranging from 222 to 241 days. One calf born to an $\mathrm{H}$ hind was stillborn and another calf born to an $\mathrm{H}$ hind died of unknown causes 30 days after birth. No birthing assistance was required in any of the years. The sex ratios (males:females) of calves were 7:8, 9:9 and 6:12 in Years 1,2 and 3 respectively, unevenly distributed across treatment groups.

Hinds on ad libitum offer generally exhibited a progressive increase in mean daily DMI throughout the

following equation:

$\mathrm{LWG}=(302[\mathrm{SE} 101]+693[\mathrm{SE} 126] \times \mathrm{ME}$ g/day $)$

with an intercept of 0.44 [SE 0.22 ] MJME $/ \mathrm{kg}^{0.75} /$ day for theoretical liveweight maintenance. An overlay of data for $\mathrm{M}$ and $\mathrm{L}$ hinds shows the positioning of most individuals above the regression line for $\mathrm{H}$ hinds (Figure 3).

Mean liveweight losses immediately following calving, and subsequent liveweight changes over lactation were similar for treatment groups within each year $(\mathrm{P}>0.05)$.

Table 1 Adjusted ${ }^{1}$ means of Day 195 CT scan measurements $(\mathrm{kg})$ for hinds in Year 1 (1998) 10 weeks after the start of imposition of feed regimens.

\begin{tabular}{lccccc}
\hline & \multicolumn{3}{c}{ Treatment } & \multirow{2}{*}{ SED } & Significance \\
\cline { 2 - 4 } & High & Medium & Low & & \\
\hline Total body fat & 8.30 & 3.79 & 3.89 & 1.10 & $* *$ \\
Total body lean & 46.54 & 45.23 & 43.84 & 1.00 & $*$ \\
Total bone & 7.07 & 7.64 & 7.50 & 0.32 & $\mathrm{~ns}$ \\
NFVC $^{2}$ & 10.83 & 11.64 & 10.60 & 0.51 & $\mathrm{~ns}$ \\
Conceptus weight $^{3}$ & 14.55 & 14.14 & 13.49 & 1.20 & $\mathrm{~ns}$ \\
Foetus weight & 7.70 & 7.05 & 6.78 & 0.73 & $\mathrm{~ns}$ \\
\hline
\end{tabular}

1 Adjusted by covariance for initial CT scan data (i.e. Day 132; Week 0 from the start of differential feeding regimens)

2 Non-fat visceral components (gut)

3 Uterus + fluid + foetus

[*P $<0.05 ; * * P<0.01 ; * * * P<0.001 ;$ ns not significant]
In general, hinds on ad libitum intakes exhibited increases in BCS leading up to calving, but $\mathrm{L}$ and $\mathrm{M}$ hinds maintained their mean BCS throughout the treatment period. CT scan measurements in Year 1 at 0 and 10 weeks from the start of indoor feeding requires indicate a significant effect of treatment on hind fatness $(\mathrm{P}<0.01)$ and total lean tissue $(\mathrm{P}<0.05)$, but not bone or gut components $(\mathrm{P}>0.05)$ (Table 
1). BCS was significantly correlated to fat and carcass lean $(\mathrm{P}<0.05)$. Trends in mean BCS between calving and weaning were variable between years, seemingly reflecting pasture quality and availability rather than any prior treatment.

CT imaging of the conceptus in Year 1 revealed no significant differences in conceptus mass between treatments, despite the fact that by day 215 , the $\mathrm{L}$ hinds exhibited 12-13\% less weight of conceptus tissues than $\mathrm{H}$ hinds (Table 1). Failure to attain significance reflects high variance of mean conceptus weights within and between treatment.

Palpable mammary tissue was not apparent before day 180 of pregnancy. Subsequent mammary development, based on lactation scores, was progressive, with peak mean scores attained at calving. The rate of mammary development varied between treatments, generally reflecting treatment effects on actual calving date. There was no evidence of carryover effects of treatments on lactation scores after calving.

Table 2 Mean gestation lengths (days) by treatment.

\begin{tabular}{lcccccc}
\hline \multicolumn{3}{c}{ Treatment } & & & \\
\cline { 2 - 4 } & High & Medium & Low & & S.E.D. Significance Range \\
\hline Year 1 & 231.3 & 234.7 & 239.2 & 2.67 & $*$ & 17 days \\
(+ outlier) & $(228.6)^{\mathrm{a}}$ & & & $(3.23)$ & $*$ & (27 days) \\
Year 2 & 233.8 & 237.0 & 236.0 & 1.45 & ns & 11 days \\
Year 3 & 232.0 & - & 233.0 & 2.25 & ns & 19 days \\
(- outlier) $^{\mathrm{b}}$ & & & $(234.4)^{\mathrm{b}}$ & 1.89 & ns & (10 days) \\
\hline
\end{tabular}

a The outlier was a stillborn calf born to a $\mathrm{H}$ hind at 218 days of gestation, possibly prematurely induced by prior anaesthetic delivery to the dam. Final analysis excluded this animal.

b The outlier was a viable calf born to $a L$ hind at 222 days of gestation, nine days earlier than any other calf in Year 3. Final analysis included this animal.

[*P $<0.05$; ** $P<0.01$; *** $P<0.001$; ns not significant]

Mean gestation length (Table 2) was significantly different between treatments in Year $1(\mathrm{P}<0.05)$ but not in Years 2 and $3(\mathrm{P}>0.05)$. Regression analyses, between and within years, was used to account or the unexpected level of variation in gestation length. There was a significant negative regression of gestation length on change in hind liveweight prior to calving, with slopes of -0.55 (SE $0.134 ; \mathrm{P}<0.01$ ) for adult hinds (Years 1 and 2 ) and -0.21 (SE 0.093; $\mathrm{P}<0.05$ ) for first calving hinds (Year 3$)$. There was no evidence $(\mathrm{P}>0.05)$ that initial hind liveweight (i.e. day 130), change in hind BCS, calf sex or sex-corrected calf birth weight was associated with gestation length.

Mean calf birth weight, adjusted for calf sex following demonstration of a significant sex effect, showed no significant treatment or year effects $(\mathrm{P}>0.05$ ). Only one viable (surviving) calf born in Year 3 was lighter than $7.0 \mathrm{~kg}$ at birth. Analysis of mean calf liveweight at 7 and 12 weeks of age revealed no significant treatment effects within year $(\mathrm{P}>0.05)$ but there were highly significant year effects $(\mathrm{P}<0.001)$, with particularly poor calf growth in Year $1(\sim 340 \mathrm{~g} /$ day $)$ compared with Year $2(\sim 440 \mathrm{~g} /$ day $)$ and Year $3(\sim 400 \mathrm{~g} /$ day).

\section{Discussion}

About 65\% of a mature breeding hinds' life is associated with pregnancy, a fact that has considerable bearing on lifetime nutritional requirements. However, pregnancy is a dynamic and changing state that exerts differential seasonal influences on nutritional requirements to ensure reproductive success. It is clear from the data on ad libitum intake in the present study, that voluntary intake of the hind increases dramatically as the conceptus develops in the last third of pregnancy. This is entirely expected given that $>70 \%$ of conceptus mass is attained over this 2-3 month period. Accordingly, total hind weight increases by over $20 \%$ during this period. The main demonstrable effect of restricted feeding to hinds over this same period was reduced liveweight gain prior to calving and failure to increase mean BCS during the indoor housing period.

The CT scan results in Year 1 of the study provide equivocal evidence that the nutritional environment during late pregnancy can influence foetal growth in red deer. In particular, nutritional deprivation appears to retard both foetal growth (recognising that the $12-13 \%$ difference in conceptus mass between $\mathrm{H}$ and $\mathrm{L}$ hinds failed to reach significance due to high between-animal variance) and mammary tissue development (i.e. lactogenesis). While the expected consequence of this would be lower birth weights of calves and poor lactational performance of hinds (Thorne et al. 1976; Albon et al. 1993), this w as not the case in the present study. There were no demonstrable effects of treatment on either calf birth weight of calf growth rate (an indicator of lactational performance). However, there was unexpectedly wide variation of gestation length, with the duration of pregnancy being negatively correlated with change in hind liveweight (and hence, nutrition level) during late pregnancy. In essence, greater liveweight gains resulted in shorter gestations, while poorer liveweight gains resulted in longer gestations.

We hypothesise, therefore, that retarded foetal development due to nutritional deprivation in late pregnancy delays lactogenesis and parturition until critical foetal mass is attained, thus enhancing the opportunities of ensuring the birth of a viable neonate 
and development of full lactational competence. The converse would be true under conditions of luxury ( $\mathrm{ad}$ libitum) nutrition. Such a compensatory mechanism would seem to be driven by a model of foetal induction of parturition/lactogenesis dependant on attainment of a specific size or stage of development being influenced by foetal growth trajectory (Liggins 1979).

There are some apparent contradictions to the hypothesis. Firstly, such variation in gestation length has not been demonstrated previously for red deer, with most studies indicating ranges of 4-5 days around a 233day mean (Guinness et al. 1971; Kelly \& Moore 1978; Krzywinski \& Jaczewski 1978). However, these observations are based on cohorts in which individuals are under similar levels of nutritional management, and unlikely to be placed under severe nutritional constraints. Secondly, there has been considerable variation in birth weight recorded previously for red deer. In several cases, such variation has been linked causally to variations in nutrition to hinds during pregnancy. Most notable, Albon et al. (1983) demonstrated a significant positive correlation between mean daily temperature during late pregnancy and subsequent mean birth weight across a number of years for red deer on the Isle of Rhum, Scotland. From this observation they contended that differential nutritional environments across years influenced mean birth weight via foetal growth. Similarly, Thorne et al. (1976) demonstrated for North American wapiti (Cervus elaphus spp.) that birth weight of calves was correlated with cow nutrition during the latter half of pregnancy. However, it is noteworthy that in the case of wapiti (Thorne et al. 1976), cows on some nutritional regimens actually lost up to $20 \%$ of the total body mass between mid-gestation and parturition. This contrasts markedly with present study in which all hinds, irrespective of the imposed level of nutrition, gained considerable weight over late pregnancy. Therefore, it is possible that the earlier studies imposed or compared nutritional levels considerably more extreme than imposed in the present study. Thus, the putative compensatory effect of variation in gestation length may only apply within certain nutritional limits.

From a deer farming perspective, there are some practical considerations arising from this study. Firstly, variation in gestation length is yet another factor that potentially influences calving seasonality and, hence, calf development. It seems logical that the nutritional influences on gestation length are most likely to contribute to variation between farms and years in calving seasonality, as most hinds within a unit are managed under the same nutritional regimen. However, there are frequent anecdotal reports of individual hinds within groups with known conception dates (e.g. hinds conceiving to artificial insemination as confirmed by ultra-sonographic foetal aging) calving well outside the expected parturition date based on the 233-day gestation length standard. This has been generally attributed to misdiagnosis of conception date but may be due to wider gestational variation than generally recognised.

Secondly, the contention that over-fatness of hinds prior to parturition is a causal factor behind difficult calvings may need to be reconsidered in light of the present study. While recognising that the o verall sample size is small, none of the $\mathrm{H}$ hinds in the study exhibited any signs of dystocia despite BCS approaching 5 (i.e. obese). This is despite the fact that they received relatively little physical exercise prior to calving due to their indoor confinement. Furthermore, there was no indication of excessive birth weights of calves born to $\mathrm{H}$ hinds.

Thirdly, if there was any carry over treatment effect on lactational performance of hinds, it was small and overshadowed by considerable variation between years. In particular, Year1 coincided with a particularly dry summer and relatively poor calf growth rates, indicating that the nutritional environment during the lactation period has the greatest overall influence on calf growth. Notwithstanding this, however, the observed treatment effect on calf birth date (i.e. gestation length) has implications on ultimate calf size on any given date. This may well be amplified by suboptimal nutritional environments after calving.

\section{REFERENCES}

Adam, C.L.; McDonald, I.; Moir, C.E.; Pennie, K. 1988. Foetal development in red deer (Cervus elaphus). 1. Growth of the foetus and associated tissues. Animal Production 46: 131-138.

Albon, S.D.; Guinness, F.E.; Clutton-Brock, T.H. 1983. The influence of climatic variation on the birth weights of red deer (Cervus elaphus). Journal of Zoology (London) 200: 295-297.

Asher, G.W.; Veldhuizen, F.A.; Morrow, C.J.; Duganzich, D.M. 1994. Effects of exogenous melatonin on prolactin secretion, lactogenesis and reproductive seasonality of adult female red deer (Cervus elaphus). Journal of Reproduction and Fertility 100: 11-19.

Audigé, L.; Wilson, P.R.; Morris, R.S. 1999. A body condition score for use in farmed red deer (Cervus elaphus). New Zealand Journal of Agricultural Research 41(4): 545-553.

Guinness, F.E.; Lincoln, G.A.; Short, R.V. 1971. The reproductive cycle of the female red deer, Cervus elaphus L. Joumal of Reproduction and Fertility 27: 427-438.

Jopson, N.B.; Kolstad, K.E.S.; Vargen, O. 1995. Computed tomography as an accurate and cost effective 
alternative to carcass dissection. Proceedings of the Australian Association of Animal Breeding and Genetics II: 635-638.

Jopson, N.B .; Thompson, J.M.; Fennessy, P.F. 1997. Tissue mobilisation rates in male fallow deer (Dama dama) as determined by computed tomography: the effects of natural and enforced food restriction. Animal Science 65: 311-320.

Kelly, R.W.; Moore, G.H. 1977. Reproductive performance in farmed red deer. New Zealand
Agricultural Science II: 179-181.

Krzywinski, A.; Jaczewski, Z. 1978. Observations on the artificial breeding of red deer. Symposium of the Zoological Society of London 43: 271-287.

Liggins, G.C. 1979. Initiation of parturition. British Medical Bulletin 35: 145-150.

Thorne, E.T.; Dean, R.E.; Hepw orth, W.G. 1976. Nutrition during gestation in relation to successful reproduction in elk. Joumal of Wildlife Management 40: $330-355$. 